\title{
Characterization of Antibiotic Resistant Salmonella spp Isolated from Chicken Eggs of Dhaka City
}

\author{
M. M. Ahmed ${ }^{1}$, M. M. Rahman ${ }^{2}$, K. R. Mahbub ${ }^{1 *}$, and M. Wahiduzzaman ${ }^{2}$ \\ ${ }^{1}$ Bangladesh Council of Scientific and Industrial Research, Dhanmondi, Dhaka 1205, Bangladesh \\ ${ }^{2}$ Department of Food Engineering and Tea Technology, Shahjalal University of Science and \\ Technology, Sylhet, Bangladesh
}

Received 19 September 2010, accepted in revised form 29 November 2010

\begin{abstract}
In present study, the occurrence of Salmonella in local chicken eggs and their pattern of antibiotic resistance were determined. 100 egg samples collected from different locations of Dhaka city were analysed and Salmonella spp were found in $8 \%$ of the samples. Among all presumptive Salmonella isolates, 8 isolates were confirmed as Salmonella enterica subsp. salamae (4\%), Salmonella enterica subsp. indica (1\%), Salmonella Paratyphi-A (1\%), Salmonella bongori (1\%) and Salmonella Choleraesuis (1\%) on the basis of serotyping and biochemical analysis. These isolates were subjected to susceptibility test against 10 antibiotic disks. All the isolates were found chloramphenicol sensitive. The highest percentage of resistance (87.5\%) was found to amoxicillin and ampicillin. Resistance against erythromycin, cephalexin, doxycycline hydrochloride, ceftazidime, doxycycline and nalidixic acid was also found significant ranging from $25 \%$ to $62.5 \%$. Salmonella isolated from egg shell surface were found more antibiotic resistant than that of egg yolk and white. The present study suggests that poultry eggs are potential reservoir of antibiotic resistant Salmonellae.
\end{abstract}

Keywords: Egg; Salmonella; Characterization; Antibiotic resistance.

(C) 2011 JSR Publications. ISSN: 2070-0237 (Print); 2070-0245 (Online). All rights reserved. doi:10.3329/jsr.v3i1.6109 J. Sci. Res. 3 (1), 191-196 (2011)

\section{Introduction}

Salmonella food poisoning is one of the most common and widely distributed diseases in the world [1,2] Outbreaks are usually associated with ingestion of contaminated food of animal origin like, poultry, meat and milk [3, 4]. Although the majority of infections results in asymptomatic or self-limited disease; however, in immuno-compromised patients, neonates and elderly, it requires antibiotic treatment [5, 6]. Recently multi-drug resistant (MDR) strains have emerged, presumably due to the extensive use of

\footnotetext{
*Corresponding author: jissanmicro_cu@yahoo.com
} 
antimicrobial agents both in human and animals. In veterinary practice, antibiotics are used in livestock production, disease prevention and as growth-promoting feed additives $[3,7]$. The use of antibiotics in animals disrupts normal flora of intestine, resulting in to emergence of antibiotic-resistant Salmonellae and their prolonged faecal shedding into the environment [8, 9]. The fatality rate in people infected with antibiotic-resistant Salmonellae is 21 times greater than that infected with non-antibiotic resistant Salmonella strains [10].

Egg-associated Salmonellosis is a public health problem. Salmonellae infect ovaries of healthy hen and contaminate eggs before shell is formed and if such eggs are consumed raw or undercooked, they cause illness. Imported birds and animals may act as source of Salmonellae to the local area leading to outbreaks [11-13]. Our present study aimed at isolation and characterization of different species of Salmonellae from chicken eggs of Dhaka city and investigation of their resistance pattern against different antibiotics.

\section{Materials and Methods}

\section{Collection and enrichment of samples}

Five local markets were selected from several places of Dhaka city i.e. New Market Kacha Bazar, Katabon Kacha Bazar, Kawran Bazar, Mohammadpur and Kazipara. Enrichment of egg samples was done according to Official Methods of Analysis of AOAC International (18 ${ }^{\text {th }}$ edition, 2005). Egg shells were washed with sterile Ringer's solution and enriched in lactose broth. Egg yolk and white was also enriched in lactose broth for 24 hours at $35^{\circ} \mathrm{C}$. For selective enrichment, $1 \mathrm{ml}$ from pre-enriched sample was transferred to $10 \mathrm{ml}$ of selenite-cystine broth and additional $1 \mathrm{ml}$ to $10 \mathrm{ml}$ tetrathionate broth and incubated at $35^{\circ} \mathrm{C}$ for 24 hours.

\section{Salmonella isolation}

Selectively enriched samples from selenite cysteine and tetrathionate broths were streaked onto xylose lysine deoxycholate (XLD) agar, Salmonella-Shigella (SS) Agar, and Bismuth Sulfite Agar (BSA). These plates were incubated at $35-37^{\circ} \mathrm{C}$ for $24 \pm 2$ hrs. After incubation, typical or suspicious Salmonella colonies were examined and further confirmed by biochemical tests including Triple Sugar Iron (TSI) agar, Lysine Iron Agar (LIA) slants and urease test. Only urease negative cultures were selected for characterization and identification by serotyping and biochemical tests including gram staining, IMViC pattern, sugar fermentation, motility, catalase and oxidase test.

\section{Serotyping of Salmonella isolates}

Salmonella positive isolates were serologically confirmed by slide agglutination test using polyvalent somatic (O) antisera kit (Remel Europe Ltd, UK). One drop of the polyvalent 
$\mathrm{O}$ antiserum was placed on the glass slide and one drop of saline suspension of 18 hours old culture was mixed with it. The slide was tilted in a back-and-forth motion for one minute and any degree of agglutination was taken as a positive reaction [14]

\section{Antibiotic susceptibility test}

The antibiotic susceptibility test was performed using agar disc diffusion assay as described by Clinical and Laboratory Standards Institute (CLSI, 2000). Antibiotics used were amoxycillin $10 \mu \mathrm{g}$, ampicillin $10 \mu \mathrm{g}$, cephalexin $30 \mu \mathrm{g}$, ceftazidine $30 \mu \mathrm{g}$, chloramphenicol $30 \mu \mathrm{g}$, doxycycline $30 \mu \mathrm{g}$, erythromycin $15 \mu \mathrm{g}$, kanamycin $30 \mu \mathrm{g}$, nalidixic acid $30 \mu \mathrm{g}$ and doxycycline hydrochloride $30 \mu \mathrm{g}$. Pure colonies of isolated Salmonellae were emulsified in normal saline and turbidity was matched with 0.5 McFarland turbidity standards. Selected antibiotic discs were placed on Mueller Hinton Agar plates seeded with bacteria. These plates were incubated at $37^{\circ} \mathrm{C}$ for 24 hours. The organisms were observed for antibiotic sensitivity based on diameters of zones of inhibition on petridishes. Susceptible and resistant isolates were defined according to the criteria suggested by the CLSI.

\section{Results and Discussion}

In this investigation, out of 100 samples analyzed, 8 were found positive ( $8 \%$ occurrence). Of the 8 isolates obtained, 6 were from eggshell and 2 from egg yolk \& white. On the basis of their biochemical characteristics, these isolates were identified as Salmonella enterica subsp. salamae (12Y), S. enterica subsp. salamae (17W), S. enterica subsp. salamae (19W), S. enterica subsp. salamae (41W), S. bongori (33Y), S. enterica subsp. indica (13W), S. Paratyphi-A (15W) and S. Choleraesuis (28W). One S. enterica subsp. salmae and one $S$. bongori were isolated from egg yolk and white. Three S. enterica subsp. salamae, one S. enterica subsp. indica, one S. Paratyphi-A (15w) and one $S$. Choleraesuis were found from egg shell. Percentage of Salmonellae occurrence on egg shell (6\%) was found higher than that of egg yolk and white (2\%) (Fig. 1).

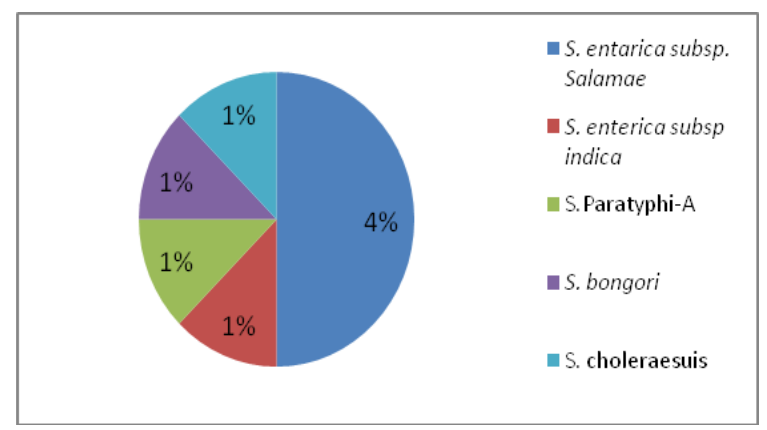

Fig. 1. Occurence of Salmonellae in egg shell and egg yolk. 
Approaches to prevent and control Salmonellosis in the food/animal industry by various means such as improved bio-security, vaccination, competitive exclusion and immuno-potentiation additionally demand antimicrobial chemotherapy. But extensive use of antibiotics in particular has lead to emergence of resistant bacteria. In the present study, all the isolates showed significant resistance to 10 commercial antibiotics.

In this study, the size of zone of inhibition of every antibiotic disc was measured in millimeter and while those zones of inhibition compared with zone diameter interpretive standards from CLSI (2000) (Table 1). Among all the antibiotics tested, amoxicillin and ampicillin showed highest resistance followed by cephalexin, erythromycin and doxycycline hydrochloride. Chloramphenical was the only antibiotic which was found sensitive to all the isolates tested.

Table 1. Antibiotic resistance patterns of isolates.

\begin{tabular}{|c|c|c|c|c|c|c|c|c|c|c|}
\hline \multirow[b]{2}{*}{ Salmonella spp. } & \multicolumn{10}{|c|}{ Name of antibiotic } \\
\hline & 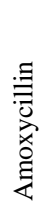 & 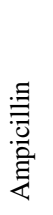 & 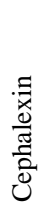 & 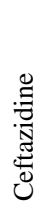 & 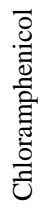 & 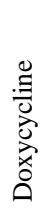 & 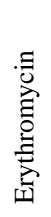 & 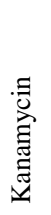 & 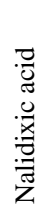 & 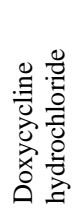 \\
\hline S. enterica subsp. salamae (12Y) & $\mathrm{R}$ & $\mathrm{R}$ & $\mathrm{R}$ & $\mathrm{S}$ & $\mathrm{S}$ & I & $\mathrm{R}$ & $\mathrm{I}$ & $\mathrm{R}$ & I \\
\hline S. enterica subsp. salamae (17W) & $\mathrm{R}$ & $\mathrm{R}$ & I & $\mathrm{R}$ & $\mathrm{S}$ & $\mathrm{S}$ & I & $\mathrm{S}$ & I & $\mathrm{S}$ \\
\hline S. enterica subsp. salamae (19W) & $\mathrm{R}$ & $\mathrm{R}$ & I & $\mathrm{S}$ & $\mathrm{S}$ & $\mathrm{R}$ & $\mathrm{R}$ & $\mathrm{S}$ & I & $\mathrm{R}$ \\
\hline S. enterica subsp. salamae (41W) & $\mathrm{R}$ & $\mathrm{R}$ & $\mathrm{S}$ & $\mathrm{R}$ & S & $\mathrm{R}$ & $\mathrm{R}$ & I & S & $\mathrm{R}$ \\
\hline S. bongori (33Y) & $\mathrm{R}$ & $\mathrm{R}$ & $\mathrm{R}$ & $\mathrm{R}$ & S & $\mathrm{S}$ & $\mathrm{R}$ & I & I & $\mathrm{S}$ \\
\hline S. enterica subsp.indica (13W) & $\mathrm{R}$ & $\mathrm{R}$ & $\mathrm{R}$ & $\mathrm{S}$ & S & $\mathrm{R}$ & I & $\mathrm{S}$ & S & $\mathrm{R}$ \\
\hline S. Paratyphi-A (15W) & $\mathrm{R}$ & $\mathrm{R}$ & $\mathrm{R}$ & $\mathrm{I}$ & S & $\mathrm{S}$ & $\mathrm{R}$ & $\mathrm{S}$ & $\mathrm{I}$ & $\mathrm{R}$ \\
\hline S. Choleraesuis (28W) & $\mathrm{I}$ & $\mathrm{I}$ & I & $\mathrm{S}$ & S & I & I & I & $\mathrm{R}$ & I \\
\hline
\end{tabular}

R- Resistant, I-Intermediate, S-Sensitive

About $87.5 \%$ isolates were found resistant to amoxicillin and ampicillin followed by erythromycin (62.5\%), cephalexin (50\%), doxycycline hydrochloride (50\%), ceftazidine (37.5\%), doxycycline (37.5\%) and nalidixic acid (25\%). While, 50\% of isolates were intermediately to kanamycin and nalidixic acid followed by $37.5 \%$ to erythromycin and cephalexin, $25 \%$ to doxycycline and doxycycline hydroclorid, and $12.5 \%$ to amoxicillin, ampicillin and ceftazidine. Kanamycin was sensitive in $50 \%$ of the isolates, ceftazidine and doxycycline were sensitive in 50\%, nalidixic acid and doxycycline hydroclorid were sensitive in $25 \%$ and cephalexin was sensitive in $12.5 \%$ of the isolates. Chloramphenicol sensitivity was $100 \%$ in all the isolates (Fig. 2). 


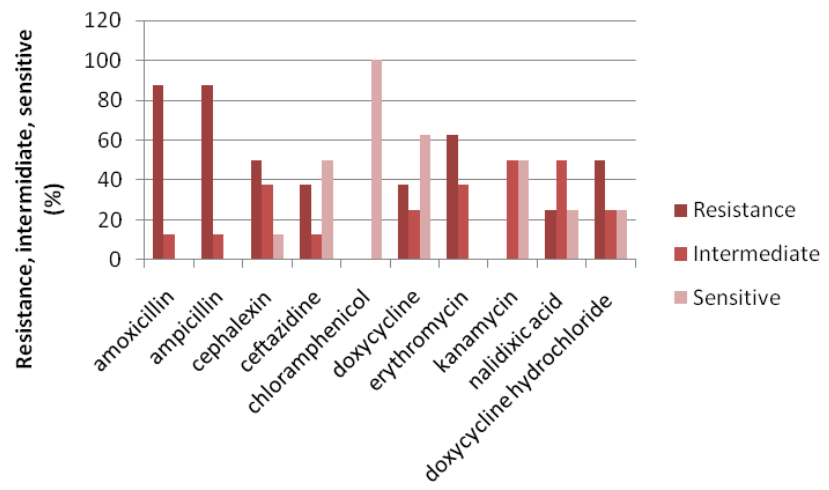

Fig. 2. Percentage of resistant, intermediate and sensitive isolates against commercial antibiotics.

The Salmonella isolates from India between 1996-99 and 2001 were reported to be $100 \%$ sensitive to chloramphenicol (15). Also, high prevalence of nalidixic acid resistance among poultry isolates (89\%) has been reported from France in the year 2000 [16]. Resistance to cephalexin was found lower than reported earlier in India [17].

The level of resistance of Salmonellae to antibiotics should be alarming to the food processing, distribution and handling of food product $[18,19]$. Therefore, it is necessary to inform people involved in the food industry as well as distributors to take care in handling the food products. Because of the widespread use of antibiotics in poultry, emergence of drug resistant Salmonellae has become a matter of concern in Bangladesh. Infection by such multi-drug resistant Salmonellae may no longer be treated by conventional therapeutic agents. In order to control Salmonella infection of poultry in Bangladesh detailed epidemiological investigation and strain identification are prerequisites [20].

The results indicate the presence of antibiotic resistant Salmonellae in chicken eggs of Dhaka city. However, further investigations with bigger sample size are needed to identify the source and cause of drug resistance.

\section{References}

1. D. C. Rodrigue, R. V. Tauxe, and B. Rowe, Epidemiol Infect. 105 (1), 21 (1990). doi:10.1017/S0950268800047609

2. T. M. Gomez, Y. Motarjemi, S. Miyagawa, F. K. Kaferstein, and K. Stohr, Foodbome salmonellosis. World Health Stat Q. 50, 81 (1997). PMid:9282390

3. M. N. Swartz, Clin. Infect. Dis. 34 (Suppl 3): S111 (2002). doi:10.1086/340248

4. R. B. Chalker, and M. J. 1. Blaser, Rev. Infect Dis. 10, 111 (1988). PMid:2832925

5. P. S. Mead, L. Slutsker, V. Dietz, L. F. McCaig, J.S. Bresee, C. Shapiro, P.M. Griffin and R.V. Tauxe, Emerg. Infect. Dis. 5, 607 (1999). doi:10.3201/eid0505.990502 PMid:10511517; PMCid:2627714

6. T. T. H. Van, G. Moutafis, T. Istivan, L. T. Tranand, and P. J. Coloe, Appl. Environ. Microbiol. 73, 6885 (2007). doi:10.1128/AEM.00972-07 ; PMid:17766455 PMCid:2074948

7. M. Sun, Sci. 226, 30 (1984). doi:10.1126/science.6566452; PMid:6566452 
8. E. J. Threlfall, FEMS Microbiol. Rev. 26, 141 (2002). doi:10.1111/j.1574-6976.2002.tb00606.x PMid:12069879

9. M. Helms and P. Vastrup, P. Gerner-Smidt and K. Mølbak, BMJ. 326 (7385), 357 (2003).

10. S. F. Altekruse, M. L. Cohen, and D. L. Swerdlow, Centers for Disease Control and prevention (CDC), (1999). http://www.cdc.gov/

11. B. Sareyyupoglu, A. A.. Çelik, A. Z. Cantekin, A. H. Yard, A. M. Akan, and A. Akçay, Avian Dis. 52 (1), 163 (2007). PMid:18077649; PMCid:2238140

12. C. Y. Yu, S. J. Chou, C. M. Yeh, M. R. Chao, K.. C. Huang, Y. F. Chang, C. S. Chiou, F. Weill, C. H. Chiu, C. H. Chu, and C. Chu, J. Clinic. Microbiol. 46 (2), 522 (2008). doi:10.1128/JCM.00709-07 ; PMid:9986881; PMCid:84593

13. A. El-Gendy, N. El-Ghorab, E. M. Elyazeed, R. A. Carlin, N. I. A. Mitry, M. M. Kay, B. A. S. J. Savarino, and L. F. Peruski, J. Clinic. Microbiol. 37, 873 (1999).

14. S. Mandal, M. D. Mandal, and N. K. Pal, Ind. J. Med. Sci. 58, 16 (2004). PMid:16409665; PMCid:2870370

15. J. Cailhol, R. Lailler, P. Bouvet, S. L. Vieille, F. Gauchard, P. Sanders, and A. Brisabois, Epidem. and Infect. 134 (1), 171, (2005). doi:10.1017/S0950268805004863

16. H. V. Murungkar, H. Rahman, A. Kumar, and D. Bhattacharya, Ind. J. Med. Res. 122, 237 (2005).

17. B. Molla, D. Alemayehu, and W. Salah, Ethio. J. Health Develop. 17, 63 (2003)

18. A. C. Kimura, M. S. Palumbo, H. Meyers, S. Abbott, R. Rodriguez, and S. B. Werner, Epidemiol. Infect. 133, 823 (2005). doi:10.1017/S0950268805004127 PMid:16181501; PMCid:2870312

19. N. Lazaro, A. Tibana, D. P. Rodrigues, E. Reis, Br. Quintaes, and E. Hofer, Pesq. Vet. Bras. 24, 57 (2004).

20. A. J. Sikder, M. A. Islam, M. M. Rahman, and M. B. Rahman, Int. J. Poul. Sci. 4 (11), 905 (2005). doi:10.3923/ijps.2005.905.910 